University of Nebraska - Lincoln

DigitalCommons@University of Nebraska - Lincoln

$1-22-2001$

\title{
Comparison of aluminum and sodium doped poly(vinylidene fluoride-trifluoroethylene) copolymers by $\mathrm{x}$-ray photoemission spectroscopy
}

\author{
B. Xu \\ University of Nebraska-Lincoln \\ Jaewu Choi \\ University of Nebraska-Lincoln, jchoi@ece.eng.wayne.edu \\ C.N. Borca \\ University of Nebraska-Lincoln \\ Peter A. Dowben \\ University of Nebraska-Lincoln, pdowben@unl.edu \\ A.V. Sorokin \\ Ivanova State University \\ See next page for additional authors
}

Follow this and additional works at: https://digitalcommons.unl.edu/physicsdowben

Part of the Physics Commons

Xu, B.; Choi, Jaewu; Borca, C.N.; Dowben, Peter A.; Sorokin, A.V.; Palto, S.P.; Petukhova, N.N.; and Yudin, S.G., "Comparison of aluminum and sodium doped poly(vinylidene fluoride-trifluoroethylene) copolymers by x-ray photoemission spectroscopy" (2001). Peter Dowben Publications. 27.

https://digitalcommons.unl.edu/physicsdowben/27

This Article is brought to you for free and open access by the Research Papers in Physics and Astronomy at DigitalCommons@University of Nebraska - Lincoln. It has been accepted for inclusion in Peter Dowben Publications by an authorized administrator of DigitalCommons@University of Nebraska - Lincoln. 


\section{Authors}

B. Xu, Jaewu Choi, C.N. Borca, Peter A. Dowben, A.V. Sorokin, S.P. Palto, N.N. Petukhova, and S.G. Yudin 


\title{
Comparison of aluminum and sodium doped poly(vinylidene fluoride-trifluoroethylene) copolymers by $x$-ray photoemission spectroscopy
}

\author{
B. Xu, Jaewu Choi, ${ }^{\text {a) }}$ C. N. Borca, and P. A. Dowben ${ }^{\text {b) }}$ \\ Department of Physics and Astronomy and the Center for Materials Research and Analysis, \\ Behlen Laboratory of Physics, University of Nebraska-Lincoln, Lincoln, Nebraska 68588-0111 \\ A. V. Sorokin \\ Department of Physics, Ivanovo State University, 153025 Ivanovo, Russia \\ S. P. Palto, N. N. Petukhova, and S. G. Yudin \\ Institute Of Crystallography, Russian Academy of Science, 59 Leninsky Prospekt, 117333 Moscow, Russia
}

(Received 13 September 2000; accepted for publication 15 November 2000)

\begin{abstract}
The chemical interaction between the simple metals, aluminum and sodium, and crystalline copolymer thin films of vinylidene fluoride (70\%) with trifluoroethylene (30\%), has been studied using x-ray photoemission spectroscopy. Aluminum and sodium metalize the polymer differently and different binding sites for the two metals can be inferred from the corresponding core level shifts. Aluminum leads to enhanced screening of final photoemission states associated with the polymer, while sodium doping strongly influences the fluorine, but perturbs the carbon backbone only slightly. (C) 2001 American Institute of Physics. [DOI: 10.1063/1.1340858]
\end{abstract}

Aluminum and sodium are both simple metals dominated by a valence $s p$ band. The aluminum atoms are believed to interact with the conjugated system to form covalent bonds and an aluminum overlayer is believed to form with $\mathrm{Al}$ evaporation with these polymers. ${ }^{1-3}$ Strong interactions were also observed in polyimides and polyesters, ${ }^{4,5}$ but the formation of an $\mathrm{Al}$ overlayer was, nonetheless, observed. For the copolymer vinylidene fluoride $(70 \%)$ with trifluoroethylene (30\%), there is compelling evidence that $\mathrm{Al}$ does not form a simple overlayer and diffusion into the polymer in the surface region does occur. ${ }^{6}$ The behavior of aluminum is in marked contrasted to the evaporation of alkali metals on many organic polymers. ${ }^{1,3,7-9}$ The appearance of states in the highest occupied molecular orbital-lowest occupied molecular orbital gap has been reported for alkali doping of a number of molecular systems ${ }^{1,3,8-10}$ including the vinylidene fluoride $(70 \%)$ with trifluoroethylene $(30 \%)$ copolymer. ${ }^{11}$ The alkali metals induced states generally act as Hubbard bands $^{11}$ in the otherwise empty band gap. There exists a large number of studies of aluminum and sodium doping of large organic molecular overlayers yet final state photoemission effects with changing metalization are rarely discussed in polymer systems.

Crystalline copolymer thin film of vinylidene fluoride (70\%) with trifluoroethylene (30\%), $\mathrm{P}(\mathrm{VDF}-\mathrm{TrFE} 70: 30)$, is a material with recognized excellent dielectric and ferroelectric properties. ${ }^{12}$ In this letter, we have compared the interaction between the low work function simple metals, aluminum and sodium, and $\mathrm{P}(\mathrm{VDF}-\mathrm{TrFE}$ 70:30) copolymer thin films.

The crystalline $\mathrm{P}(\mathrm{VDF}-\mathrm{TrFE}$ 70:30) films were formed

\footnotetext{
${ }^{a)}$ Also at: Center for Advanced Microstructures \& Devices, Louisiana State University, 6980 Jefferson Highway, Baton Rouge, LA 70806.

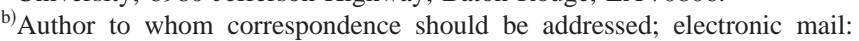
pdowben@unl.edu
}

by Langmuir-Blodgett monolayer deposition from a water subphase $^{12,13}$ and deposited on silicon for $\mathrm{x}$-ray photoemission spectroscopy (XPS) studies described in detail elsewhere. ${ }^{14}$

In Fig. 1 we present a series of angle-resolved carbon $1 s$ XPS spectra of 5 monolayer (ML) film of P(VDF-TrFE 70:30) from a clean sample [Fig. 1(a)] and from an aluminum doped sample [Fig. 1(b)] as well as $\mathrm{Al} 2 p$ spectra from the aluminum-doped sample [Fig. 1(c)]. For the clean copolymer sample, the position of the higher binding energy $(290.7 \mathrm{eV}) \mathrm{C} 1 s$ XPS peak is independent of emission angle, while the $\mathrm{C} 1 s$ peak of the lower binding energy shifts with increasing emission angles from $285.9 \mathrm{eV}$ at $0^{\circ}$ emission angle to less than $285.1 \mathrm{eV}$ at $60^{\circ}$ emission angle, as seen in Fig. 1(a). There is also a weak feature at $288.4 \mathrm{eV}$ binding energy.

A correct assignment of chemical states to specific core level binding energies requires a clear distinction between initial and final states in photoemission (which is difficult in polymers) and was not undertaken in previous core level photoemission studies for poly- $\left[-\mathrm{CH}_{2}-\mathrm{CF}_{2}-\right]-$ and poly-[-CHF- $\left.\mathrm{CF}_{2}-\right]-.{ }^{15}$ Conduction band spectroscopy ${ }^{11,16,17}$ provides strong evidence that the density of states near the Fermi level at the surface region is greater than that in the bulk at room temperature. We can reasonably anticipate greater improved core-hole screening (and final state photoemission binding energy shifts) at the surface than in the bulk. In angle-resolved XPS (ARXPS), increasing the emission angle increases the surface sensitivity. So the main feature of $\mathrm{C} 1 s$ core level (located at $285.9 \mathrm{eV}$ at $0^{\circ}$ emission angle) shifts to lower binding energy as a result of improved surface screening effect. Attributing the $\mathrm{C} 1 \mathrm{~s}$ peak located at $290.7 \mathrm{eV}$ to an unscreened final state in this picture is supported by the suppression of this state with $\mathrm{Al}$ doping and the enhancement of this state with Na doping, as discussed later. 


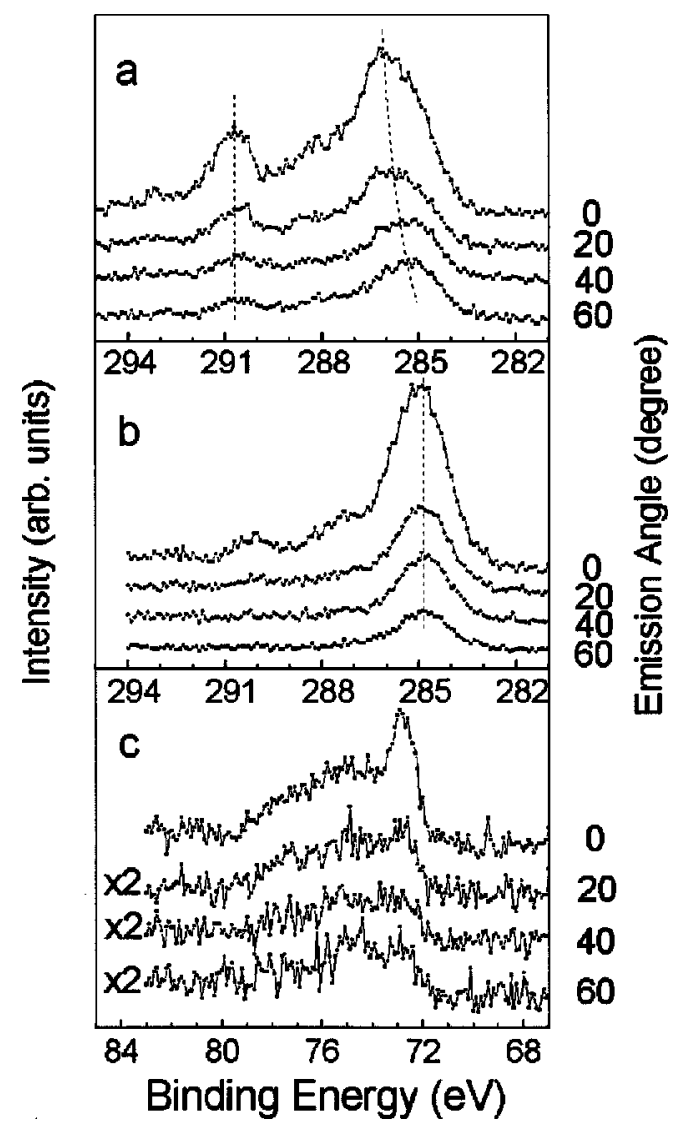

FIG. 1. Angle-resolved X-ray photoemission spectra for a $5 \mathrm{ML}$ crystalline $\mathrm{P}(\mathrm{VDF}-\mathrm{TrFE}$ 70:30) copolymer thin film. (a) The C $1 s$ core level from clean $\mathrm{P}(\mathrm{VDF}-\mathrm{TrFE})$ as a function of emission angle. (b) The angle-resolved $\mathrm{C} 1 s$ core level at several different emission angles following aluminum deposition and $6 \mathrm{~h}$ annealing at $393 \mathrm{~K}$. (c) Al $2 p$ core level immediately following deposition on $\mathrm{P}(\mathrm{VDF}-\mathrm{TrFE})$ at room temperature.

In Fig. 2, $\mathrm{C} 1 s, \mathrm{~F} 1 s$, and $\mathrm{Na} 1 s$ core levels are shown for different sample conditions. All the spectra were taken at normal emission. The sodium, as deposited on the $5 \mathrm{ML}$ film of $\mathrm{P}(\mathrm{VDF}-\mathrm{TrFE} 70: 30)$ at $200 \mathrm{~K}$, exhibits a $\mathrm{Na} 1 s$ line shape with two distinct features characteristic of an inhomogeneous distribution of alkali metal, which also appears for aluminum doping. There is a clear plasmon like loss feature at $1077 \mathrm{eV}$ binding energy characteristic of sodium clustering. ${ }^{11,18}$ Annealing the film to $350 \mathrm{~K}$ leads to a far more uniform distribution of alkali metal without any evidence of metallic cluster formation, as seen from Fig. 2. The $\mathrm{C} 1 s$ and $\mathrm{F} 1 s$ core levels all change dramatically after sodium doping, as in the aluminum doping case, but with some differences. The lower binding energy $\mathrm{C} 1 s$ peak at 285.9 $\pm 0.1 \mathrm{eV}$ and $\mathrm{F} 1 s$ peak at $688.2 \pm 0.2 \mathrm{eV}$ both shift to the lower binding energies: $285.3 \pm 0.1 \mathrm{eV}$ and $686.2 \pm 0.2 \mathrm{eV}$, respectively. The C $1 s$ core level feature at $290.7 \pm 0.5 \mathrm{eV}$ shifts to higher binding energy: $291.1 \pm 0.2 \mathrm{eV}$ with sodium doping. This carbon core level (at $290.7 \mathrm{eV}$ binding energy) therefore cannot be associated with the $\mathrm{C}-\mathrm{F}_{2}$ bonds, and the literature assignment, based on initial state chemical configurations, ${ }^{15}$ is questionable. Final state effects, like screening, are implicated in the changes in intensity and core level binding energy shift of this carbon core feature.

The core level spectra following deposition of a nominal 5 - $\AA$-thick aluminum overlayer (as determined from the thin film thickness monitor) on 5 ML thick copolymer P(VDFDownloaded 06 Sep 2006 to 129.93.16.206. Redistribution subjec

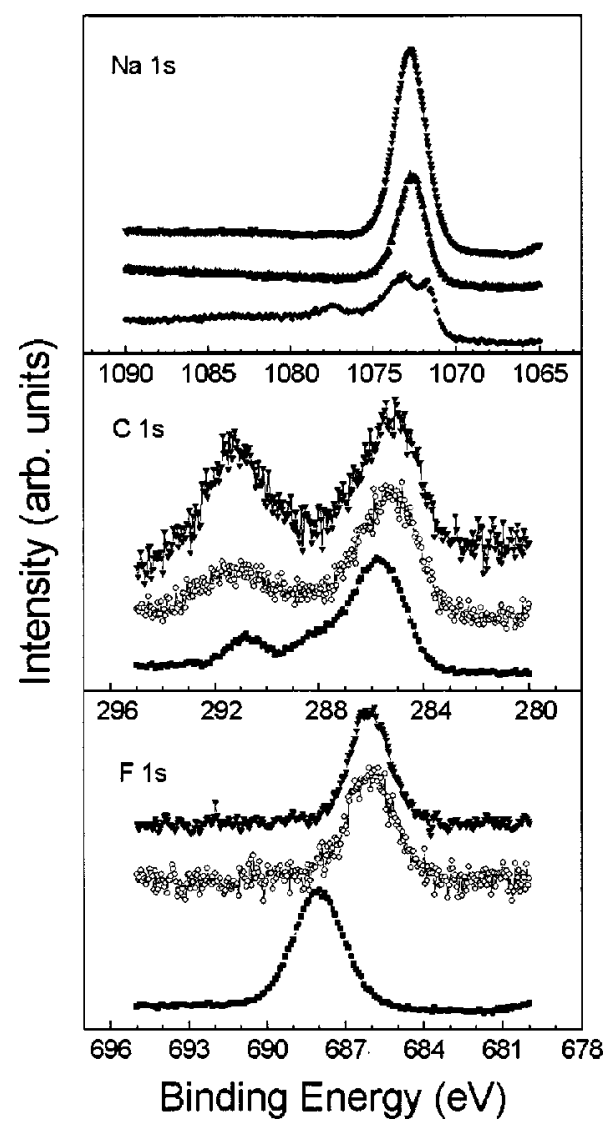

FIG. 2. Na $1 s, \mathrm{C} 1 s$, and F $1 s$ x-ray photoemission spectra of the $5 \mathrm{ML}$ crystalline $\mathrm{P}(\mathrm{VDF}-\mathrm{TrFE})$ copolymer thin film. Spectra for $\mathrm{Na} 1 s$ are from 1 ML Na freshly deposited and unannealed $(-)$ and then annealing to $423 \mathrm{~K}$ $(\mathbf{\Lambda})$, also from 4 ML Na (equivalent) doped and annealed sample $(\boldsymbol{\nabla})$. Spectra for $\mathrm{C}$ and $\mathrm{F}$ are from clean copolymer sample ( $\mathbf{\square}), 2 \mathrm{ML}$ Na doped and annealed sample $(\bigcirc)$ and 4 ML Na doped and annealed sample $(\boldsymbol{\nabla})$.

TrFE 70:30) film at room temperature is shown in Fig. 3. The aluminum XPS core level spectrum from a fresh aluminum deposition exhibits an $\mathrm{Al} 2 p$ line shape with two distinct features: a sharp peak located at $72.8 \mathrm{eV}$ again suggesting the formation of metallic clusters ${ }^{6,19}$ and a broad peak at a higher binding energy $(\sim 76 \mathrm{eV})$, as seen in Fig. 3. The distribution of aluminum in the copolymer thin film was investigated by $\mathrm{ARXPS}^{6}$ and shown to be quite uniform in 5 ML P(VDF-TrFE 70:30) copolymer thin films.

The XPS C $1 s$ and F $1 s$ core level line shapes and binding energies of the copolymer film change following deposition of aluminum, but change little further when the sample is annealed at $393 \mathrm{~K}$ after aluminum deposition. As shown in Fig. 3, all peaks for $\mathrm{C} 1 s$ and $\mathrm{F} 1 s$ shift to lower binding energy after aluminum doping. The decrease in binding energy for all the $\mathrm{C} 1 s$ as well as the $\mathrm{F} 1 s$ core levels is similar: about $0.5-1 \mathrm{eV}$. Another important change is the ratio of the intensity of $\mathrm{C} 1 \mathrm{~s}$ peak located at $290.7 \mathrm{eV}$ binding energy to that located at $285.9 \mathrm{eV}$ binding energy. The $\mathrm{C}$ $1 s$ core level, attributable to an unscreened final state at $290.7 \mathrm{eV}$ in the undoped material, is strongly suppressed altogether with $\mathrm{Al}$ doping.

With sodium doping, the F $1 s$ core level shifts about 2 $\mathrm{eV}$ while the lower binding energy $\mathrm{C} 1 s$ peak $(285.9 \mathrm{eV})$ shifts about $0.6 \mathrm{eV}$. For aluminum doping, F $1 s$ shifts about $0.4 \mathrm{eV}$ while the lower binding energy $\mathrm{C} 1 s$ peak $(285.9 \mathrm{eV})$ shifts about $0.9 \mathrm{eV}$. Furthermore, the ratio of the intensity of o AIP license or copyright, see http://apl.aip.org/apl/copyright.jsp 


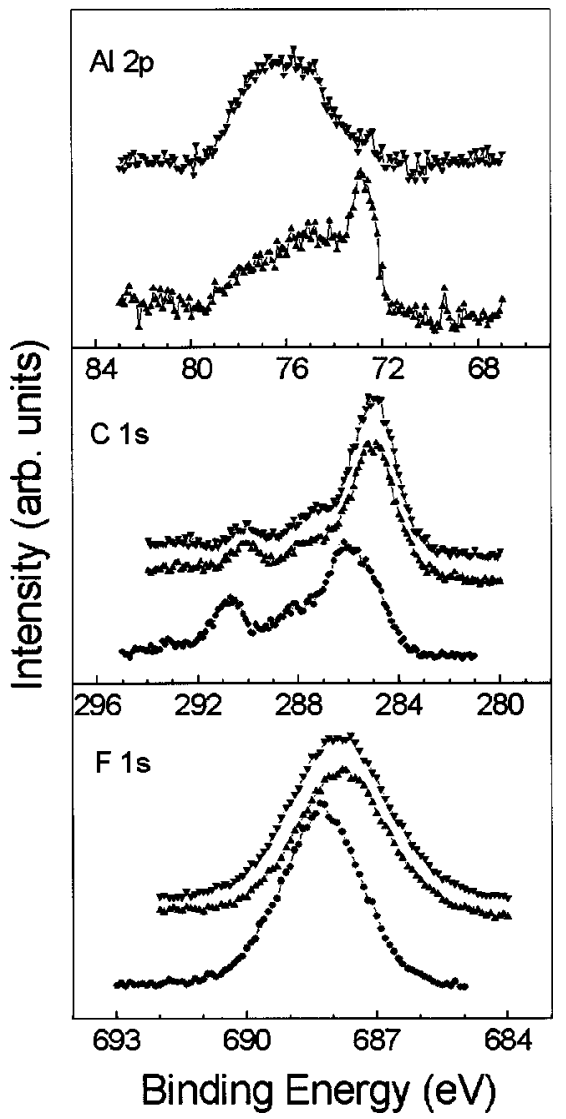

FIG. 3. Al $2 p, \mathrm{C} 1 s$, and F $1 s$-ray photoemission spectra of the 5ML crystalline $\mathrm{P}(\mathrm{VDF}-\mathrm{TrFE})$ copolymer thin film. The data from clean $\mathrm{P}(\mathrm{VDF}-\mathrm{TrFE})$ copolymer film $(\mathbf{)})$, aluminum deposited film without annealing $(\boldsymbol{\Delta})$ and aluminum deposited film followed with $6 \mathrm{~h}$ annealing at $393 \mathrm{~K}(\boldsymbol{\nabla})$ are shown in the appropriate panels. The emission is normal to the surface.

the $\mathrm{C} 1 s$ peak located at higher binding energy $(290.7 \mathrm{eV})$ to that located at lower binding energy $(285.9 \mathrm{eV})$ increases with increasing sodium doping but decreases with aluminum doping. The aluminum doping appears to lead to a copolymer film that has been metallized to the point where all the $\mathrm{C}$ $1 s$ and $\mathrm{F} 1 s$ core level binding energies are reduced. This provides further support to our contention that screening is a dominant effect on the binding energy. If the aluminum bonded strongly with one specific location along the polymer backbone, then the core levels would not shift to lower binding energies so uniformly. It is $\mathrm{Na}$ doping that leads to a more specific site interaction with $\mathrm{P}(\mathrm{VDF}-\mathrm{TrFE}$ 70:30) copolymer thin films so that a uniform screening of polymer backbone atoms does not occur.

Previous work with sodium doping in $\mathrm{P}(\mathrm{VDF}-\mathrm{TrFE}$ 70:30) copolymer thin films indicates that the strong sodium interaction with fluorine, detailed here, does not lead to $\mathrm{C}-\mathrm{F}$ bond cleavage or the formation of a $\mathrm{NaF}$ salt. The valence band photoemission features of the $\mathrm{P}(\mathrm{VDF}-\mathrm{TrFE}$ 70:30) copolymer, due to the molecular orbitals, are seen to change dramatically with substantial chemical modification of the $\mathrm{P}\left(\mathrm{VDF}-\mathrm{TrFE}\right.$ 70:30) copolymer sample. ${ }^{20}$ In comparison, $\mathrm{Na}$ doping of $\mathrm{P}(\mathrm{VDF}-\mathrm{TrFE} 70: 30)$ copolymer thin films al- ters the photoemission molecular orbital features only very slightly: the most significant changes are the introduction of two lower Hubbard-like bands. ${ }^{11}$ These valence band changes, in photoemission, are not characteristic of a molecular functional group change. In addition, the binding energies of $\mathrm{F} 1 s$ and $\mathrm{Na} 1 s$, in our experiment, are quite different from literature values for $\mathrm{NaF}^{21}$

From these differences between $\mathrm{Na}$ and $\mathrm{Al}$ doping on the core level binding energies, we can conclude that, although in both cases the metal atoms go into the copolymer film fairly uniformly after a slight amount of annealing (no clustering or preference for surface versus bulk sites), the two metals have different interactions with the copolymer backbones and probably occupy different bonding sites. Sodium atoms strongly interaction with fluorine atoms and donate electron(s) or fractional charge most directly to the fluorine atoms. The electrons on copolymer carbon backbone become more localized with sodium doping, and this is indicated by the increasing intensity of unscreened $\mathrm{C} 1 \mathrm{~s}$ final state at $290.7 \mathrm{eV}$ that shifts to higher binding energy: $291.1 \mathrm{eV}$. The localization of charge with sodium doping, rather than increasing apparent metallization, helps accounting for the large correlation energy suggested by the presence of Hubbard bands apparent with sodium doping of P(VDF-TrFE 70:30) copolymer thin films reported previously. ${ }^{11}$ For aluminum doping, the metal atoms prefer to interact with delocalized influence along the copolymer backbones, and this leads to a better core-hole screening, for both fluorine and carbon atoms, in addition to suppressing the unscreened $\mathrm{C} 1 \mathrm{~s}$ state.

This work was supported by the ONR, the Nebraska Research Initiative, the Russian Foundation for Research (No. 99-02-16484) and the Inco-Copernicus Program (No. IC15-CT96-0744). The authors would like to thank V. Fridkin and S. Ducharme for their help.

${ }^{1}$ P. Dannetun et al., J. Chem. Phys. 100, 6765 (1994).

${ }^{2}$ P. Dannetun et al., J. Chem. Phys. 99, 664 (1993).

${ }^{3}$ M. Fahlman et al., Synth. Met. 78, 237 (1996).

${ }^{4}$ P. S. Ho et al., J. Vac. Sci. Technol. A 3, 739 (1985).

${ }^{5}$ M. Bou, J. M. Martin, T. Le Mogne, and L. Vovelle, in Metallized Plastics 2, edited by K. L. Mittal (Plenum, New York, 1991), p. 219.

${ }^{6}$ B. Xu et al., J. Chem. Phys. 114 (2001) (in press).

${ }^{7}$ M. Lögdlund et al., Phys. Rev. Lett. 63, 1841 (1989).

${ }^{8}$ M. Fahlman et al., Chem. Phys. Lett. 214, 327 (1993).

${ }^{9}$ M. Lögdlund et al., Phys. Rev. Lett. 70, 970 (1993).

${ }^{10}$ T. Miyamae et al., J. Electron Spectrosc. Relat. Phenom. 78, 399 (1996).

${ }^{11}$ J. Choi et al., Phys. Rev. B 59, 1819 (1999).

${ }^{12}$ L. M. Blinov et al., Usp. Fiz. Nauk 43, 243 (2000); A. V. Bune et al., Nature (London) 391, 874 (1998).

${ }^{13}$ S. Palto et al., Ferroelectr. Lett. Sect. 19, 65 (1995); L. M. Blinov, Sov. Phys. Usp. 31, 623 (1988).

${ }^{14}$ D. N. Mcllroy et al., Phys. Rev. B 54, 17438 (1996).

${ }^{15}$ D. T. Clark et al., J. Polym. Sci., Polym. Chem. Ed. 11, 389 (1973).

${ }^{16}$ J. Choi et al., Phys. Lett. A 249, 505 (1998).

${ }^{17}$ J. Choi et al., Phys. Rev. B 61, 5760 (2000).

${ }^{18}$ T. Reiners et al., Phys. Rev. Lett. 74, 1558 (1995).

${ }^{19}$ G. E. McGuire et al., Inorg. Chem. 12, 2451 (1973).

${ }^{20}$ Jaewu Choi et al., Appl. Phys. Lett. 76, 381 (2000).

${ }^{21}$ W. E. Morgan, J. R. Van Wazer, and W. J. Stec, J. Am. Chem. Soc. 95, 751 (1973). 